\title{
JULIO CAMBA, CRÍTICO LITERARIO DEL MODENISMO
}

\author{
José ANTONIO LLERA
}

I.E.S. Juan Carlos I de Ciempozuelos (Madrid)

El hombre es una máscara, no sólo para los demás, sino para sí mismo. No hay manera de averiguar claramente en dónde empieza su realidad y en dónde acaban sus ficciones.

(PÍO BAROJA)

\section{RESUMEN}

Julio Camba es un autor conocido por sus crónicas viajeras impregnadas de humorismo que empieza a escribir en la primera década del siglo XX. Sin embargo, anteriormente publicó en el semanario ácrata Revista Blanca y en el diario republicano El País una serie de reseñas literarias sobre poetas modernistas —Rubén Darío, Francisco Villaespesa, Manuel Machado, Amado Nervo- y algún manifesto literario que revelan la evolución de su estilo y de su pensamiento. El análisis de estos artículos permite conocer a un escritor en principio partidario del anarquismo ortodoxo y crítico con el movimiento modernista, que posteriormente se decanta por la defensa de los valores de la literatura modernista e incorpora la ironía a su visión del mundo.

Palabras claves: Julio Camba, Modernismo, crítica literaria.

\begin{abstract}
Julio Camba is a well-known author by his travelling chronicles impregnated with humour who starts writing in the first decade of the XXth century. Nevertheless, previously he published in the anarchistic magazine Revista Blanca and in the republican newspaper El País some literary reviews on poetry — Rubén Darío, Francisco Villaespesa, Manuel Machado, Amado Nervo- and some literary manifestoes that they reveal both his style and his thought's development. The interpretation of these articles allows to know a writer who praised orthodox anarchism and disapproved of Modernismo. Afterwards, Camba defended the values of Modernismo and incorporated irony into his vision of the world.
\end{abstract}

Key words: Julio Camba, Modernismo, literary criticism. 


\section{CAMBA ANTES DE CAMBA}

En 1903, sin haber cumplido aún los veinte años, Julio Camba es un aprendiz de jacobino que acaba de llegar al Madrid provinciano, bullicioso y noctámbulo de principios de siglo. Le gusta la bohemia y le atrae la poesía, pero apenas puede pagarse la pensión. Lo han expulsado de Argentina por actividades anarquistas y nada más llegar a la capital se agarra como un clavo ardiendo a las primeras colaboraciones periodísticas que se le ofrecen en la prensa revolucionaria. Modos de vivir que no daban de vivir, diríamos parafraseando a Larra.

Pasado el tiempo, Camba evitará hablar a sus amistades de aquellos años; incluso se molestará cuando le inquieran acerca de sus escritos de juventud. Ni que decir tiene que ninguno de estos artículos llegó a editarse nunca en forma de libro. Tampoco se incluyen, claro está, en las Obras Completas editadas por Plus Ultra en 1948, que como es sabido responden mejor al rótulo de obras selectas. Los artículos que se recogen en ellas frisan ya el primer decenio del siglo Xx y son los que han centrado abrumadoramente el interés de la crítica. Los artículos anteriores se consideran parte de la etapa de formación del humorista y se suelen agrupar en un cajón de sastre denominado «escritos anarquistas». Pese al personaje que él mismo de construyó en sus crónicas —el de viajero más inmerso en el ajetreo de la vida que en los libros-, rebuscando en las hemerotecas me llaman la atención, además de los artículos políticos, un buen número de reseñas literarias sobre las que quiero ocuparme en estas páginas. Estas reseñas, cercanas algunas al manifiesto, iluminan la trayectoria vital y literaria de Camba, aún bastante desconocida, y son a la vez una notable carta de navegación que ayudan a reconstruir el contexto en el que se produce la recepción del Modernismo en España.

\section{DE LA ANARQUíA A LA CRÍTICA LITERARIA PROMODERNISTA}

\subsection{Revista Blanca (1903)}

La Revista Blanca empezó a publicarse en 1898 en Madrid bajo la dirección del anarquista Juan Montseny (Federico Urales) con el apoyo económico de Ferrer Guardia. Incluía en su plantilla a prestigiosos intelectuales como Francisco Giner de los Ríos, Miguel de Unamuno, Manuel Cossío o Gumersindo Azcárate, junto a representantes del movimiento libertario como Anselmo Lorenzo, Pedro Corominas, Juan Brossa, Tárrida del Mármol y Ricardo Mella. La fe anarquista de Camba, aunque fuera de pega 
según el retrato malicioso y picudo de Cansinos Assens ${ }^{1}$, prometía buen acomodo entre sus páginas. Con el título de «Generalidades» firma el 15 de junio de 1903 (núm. 120) un artículo satírico contra el movimiento modernista, que a la sazón concitaba defensores —Juan Ramón Jiménez acaba de fundar Helios en abril de ese año- y furibundos detractores en la prensa. Entre estos últimos había estado Clarín desde su sección «Paliques» en Madrid Cómico. Es muy dudoso, no obstante, que Camba tuviera una idea mínimamente formada acerca del modernismo. Es de suponer que habría leído algún poema en la prensa, pero no mucho más. Creo más bien que bajo la ortodoxia anarquista de Urales se dejó llevar por las directrices de su patrón. ¿Qué otra cosa le podríamos pedir a un joven que trataba de ganarse la vida? Entre 1900 y 1902 Urales había ido publicando en la Revista Blanca fragmentos de La evolución de la filosofía en España donde tachaba a los modernistas de extravagantes y decadentes ${ }^{2}$. El texto de Camba se amolda a esa retórica panfletaria. Todo hace pensar que habla por boca de ganso:

Mal o bien, nuestros padres cumplieron en la literatura su deber de hombres: crear. La juventud de ahora, no. Falta de vigor, en vez de ir al arte y fecundarlo, derrámase estérilmente frente a él en palabras hueras y en estrofas vacías. No es labor de artista su obra. Es tarea de artífices, de retóricos, que aman la forma sin preocuparse de los conceptos.

[...] Andan por ahí, no obstante, mil libros de poesías, con versos muy largos al pie de versos muy cortos, y no falta quien se asuste de este pseudoanarquismo poético. Observando es fácil, empero, echar de ver que no hay tal anarquismo, sino una estafa miserable perpetrada en la inteligencia del grueso público por nuestra pequeña trouppe modernista.

La vacuidad de la forma en perjuicio del contenido, la experimentación métrica puramente artificial, sin ideas, estéril. Éste es el argumento definitivo sobre el que Camba fundamenta su censura del movimiento que abraza cada vez con más fuerza la juventud. La asociación con el anarquismo va a ser disuelta también a la luz del credo ácrata ${ }^{3}$ : la libertad y la rebeldía que proclama el modernismo son sólo epidérmicas, ya que carecen de un trasfondo social verdadero; desde esta óptica, el esteticismo modernista le incapacita para transformar a la sociedad y al individuo. La querella se

1 Vid. Rafael CANSINOS AssEns, La novela de un literato. (Hombres-Ideas-Efemérides-Anécdotas), I, Madrid, Alianza, 1982, pp. 168-177 у 294-295.

${ }^{2}$ Federico URALES, La evolución de la filosofía en España, preliminar de Rafael Pérez de la Dehesa, Barcelona, Laia, 1977. Vid., del mismo autor y publicado poco antes del texto de Camba, «El arte, el amor y la mujer en el Ateneo de Madrid», Revista Blanca, 1 de abril, 1903.

3 Sobre la teoría anarquista del arte, véase José Álvarez JunCO, La ideología política del anarquismo español (1868-1910), Madrid, Siglo XXI, 1991 (2a ed. corregida), pp. 79 y ss. 
concentra en la noción de forma, incapaz de abrigar un arte realista comprometido con su tiempo:

¡La belleza! ¡El arte! ¡El arte por el arte! ¡El arte por la belleza!... ¡Dios de Dios, que serie de majaderías! El arte, como todo lo que existe, es vida, y la vida tiene que reflejarse en el arte, si no se quiere hacer un arte muerto.[...]. La forma es, simplemente, carne, y todos sabemos que, sin sangre, la carne es algo muy frío y muy triste.

Dejando a un lado la paradoja de la interjección (un anarquista clamando a Dios ${ }^{4}$ ), está claro que el anarquismo más ortodoxo no podía entender ni el nihilismo, ni la armonía musical sin enunciados asertivos. A esta visión de la forma poética, sin duda estrecha, los anarquistas oponían una exaltación del vitalismo. Veamos la estrategia argumentativa que utiliza Camba. A la serie de alegorías primero genética (los padres de la tradición y la juventud creadora desnaturalizada) y después orgánica (el cuerpo recluido en el mármol frío, sin vida), le sucede ahora la alegoría vegetal que remata la tesis con un nuevo ejemplo:

El modernismo español es una planta degenerada, un pobre lirio sin savia que no puede echar raíces en ningún jardín y que vegeta únicamente en el invernadero cerebral de nuestra juventud artística.

¿A qué obedecerá tanta miseria de espíritu? ¿Será, tal vez, el clima su causa determinante? ¿Será la educación? ¿Será el ambiente? Yo sólo veo en todo ello un agudo morbosismo intelectual. Nuestra juventud odia las ideas, no por convicción, ni siquiera por temperamento, sino por su incapacidad para comprenderlas, por su impotencia para amarlas.

«Planta degenerada». La alusión a lo degenerado debió de resultar muy familiar para el lector de la Revista Blanca. Un año antes, en 1902, Nicolás Salmerón había vertido al castellano Degeneración, de Max Nordau, quien psicologiza ciertas actitudes estéticas individualistas y políticas tachándolas de locura patológica. Camba, como otros autores de la época, se apropia del término ad hoc. Y sin embargo, pese a su condena del modernismo y del simbolismo, Camba hace una excepción: Vicente Medina, poeta melancólico, regionalista y de tendencia reivindicativa. En 1902 publicó $L a$ canción de la vida y Eduardo Gómez Baquero (Andrenio), uno de los críticos más prestigiosos de la época, elogió su poesía ${ }^{5}$. A buen seguro Camba hallaría muchas similitudes con los poemas que él había publicado en

${ }^{4}$ La paradoja ya la había advertido Lily LiTVAK, Musa libertaria. Arte, literatura y vida cultural del anarquismo español (1880-1913), Barcelona, Bosch, 1981, p. 134.

5 Rubén Darío, sin embargo, se muestra más crítico: «Lo monocorde de su manera llega a fatigar, con la repetición de la queja, una queja continua» («Los poetas», España Contemporánea, 24-VIII-1899). 
la prensa gallega ${ }^{6}$. A Medina le salva la dimensión social de su lírica. Es por ello un poeta sano, no degenerado:

Yo sólo conozco en España un poeta de espíritu joven: Vicente Medina. Lleno de salud y de fe ha hecho suyo el sufrimiento de toda la humanidad desheredada y lo ha trasladado al arte, creando páginas vigorosas por las que fluye una corriente de pasión profunda y de la que asciende al cielo un grito de rebeldía suprema.

El artículo se cierra con una proclama política a favor del igualitarismo y de la justicia social:

Hay un bloque, un enorme bloque de masa palpitante al que se deben consagrar todas las energías del entendimiento: la Humanidad. Hoy la vemos triste, dolorida, fea, bañada en el pus de sus corrupciones, inundada en la sangre de sus infortunios. Vayamos a ella, compañeros de juventud, con el pincel, con el buril, con la pluma. Plasmemos en su carne una figura hermosa, inyectemos en sus venas una sangre fuerte, imprimamos a su rostro un gesto de sana alegría.

Y cuando consigamos vivificar la Humanidad, haciéndola dichosa y feliz, habremos obtenido el ideal supremo de la belleza y del arte.

Después de analizar algunos de sus textos, Litvak se refiere al pensamiento cambiano como síntesis entre «nietzschenismo, stirnerismo y movimiento obrero libertario» ${ }^{7}$. La asimilación de Nietzsche no es ni mucho menos completa, pero su influencia me parece incontrovertible, como en gran parte del anarquismo español, con los oportunos matices ${ }^{8}$. No creo, en cambio, que el párrafo que acabo de citar pudiera salir de la pluma de un seguidor de Max Stirner, quien exalta al yo como creador de valores y tiene a la Humanidad por un concepto espectral, vacío. El joven Camba recién llegado de Buenos Aires parece más cerca del anarquismo solidario de Kropotkin y de Tolstoi, ampliamente difundidos en la Revista Blanca. (Recordemos que Azorín traduce Las Prisiones de Kropotkin en 1897).

Sin embargo, pronto veremos que este discurso no es sino una máscara. Cansado de la línea editorial de la Revista Blanca y del dirigismo doc-

${ }^{6}$ Cfr. Almudena Revilla Guijarro, Periodismo y literatura en la obra de Julio Camba, Pontevedra, Servicio de Publicaciones de la Diputación Provincial de Pontevedra, pp. 485-486.

${ }^{7}$ Litvak comete un error -ya presente en Álvarez Junco (op. cit., p. 80) - al atribuir a Julio Camba unos artículos de Acracia firmados en 1886 por una ambigua inicial C. Es evidente que Camba no pudo escribirlos, puesto que nació en 1884.

${ }^{8}$ De hecho, Camba critica en un artículo posterior publicado en la Revista Blanca también en 1903 («Sobre la emancipación de la mujer», núm. 123, 15 de agosto) la misoginia del pensador germano. Véase José ÁlvaREZ JunCO, op. cit., pp. 151 y ss.; y Gonzalo SobejAnO, Nietzsche en España, Madrid, Gredos, 1967. Sobejano, que al parecer desconoce estos primeros textos de Camba, juzga a nuestro escritor como antinietzscheano dejándose llevar por la ironía que descarga contra el filósofo alemán en una de sus crónicas posteriores. 
trinal de Urales, Julio Camba funda su propia publicación junto con el tipógrafo Antonio Apolo: El Rebelde. Aunque no me voy a detener en ello ${ }^{9}$, es obvio que el anarquismo de Camba se radicaliza. Su pathos colérico y apelativo recoge toda la tópica del programa libertario: moral natural en oposición a la falsa moral burguesa, negación de la autoridad del Estado e hipóstasis del Ideal. Artículos como «La cobardía española» (25 de agosto, 1904), por su anarco-elitismo, lo aproximan a Nietzsche y a cierto regeneracionismo, alejándolo de posiciones obreristas: «[...] en medio de esta abulia colectiva, la voluntad de unos cuantos se ha levantado fiera y gallarda». Camba, que fue procesado varias veces por delitos de imprenta, se ganó bastantes enemigos. El nombre de nuestro escritor aparece en un curioso libelo de poco más de treinta páginas titulado Los hampones de la literatura (1904), firmado con pseudónimo (Chiquiznaque) y que se vendía a 60 céntimos de peseta:

Para conocer su fiereza de anarquista convencido, hay que verlo comer un cubierto de peseta en el restaurant Imperial. El pan que le sobra, se lo mete en el bolsillo.

Es un carácter.

Es un carácter de sinvergüenza que no tiene fin. Enemigo de la dinamita, emplea el sable.

Sólo ha escrito obras para Apolo.

La aventura de El Rebelde dura poco. Su último número aparece el 28 de noviembre de 1904. Roberto Castrovido, el director de El País, le abre las puertas al atrevido agitador. Aún tiene ganas de batalla, pero poco a poco se irá alejando de la militancia anarquista.

\subsection{El País (1905-1907)}

\subsubsection{Doctrina literaria}

El País era un diario republicano de filiación lerrouxista (del político radical se reirá Camba años más tarde en una de sus crónicas italianas). Nuestro autor firma su primer artículo el 26 de enero de 1905. Se nota un progresivo alejamiento del anarquismo hacia las aguas más tibias de la polémica literaria y de la reseña. Si bien se ocupa de narradores como Gorki y Baroja, la poesía modernista absorbe la mayor porción de textos. Naturalmente, el joven Camba ha evolucionado, conoce de primera mano la lírica del momento y ha discutido con los poetas en las tertulias. Ahora habla de ellos con admiración.

9 Véase Mario Clavel Blanch, «Julio Camba, escritor anarquista», en Fidel LóPEZ CRIADO (ed.), Julio Camba, el escritor y su circunstancia, A Coruña, Ayuntamiento de A Coruña, 2004, pp. 73-80. En julio de 1905 Camba inicia también otra efímera empresa editorial: La anarquía literaria, revista cultural próxima al Modernismo (vid. Almudena Revilla Guijarro, op. cit., p. 49). 
Anarquismo y modernismo compartían una misma actitud de rechazo del presente ${ }^{10}$. En términos generales constituían la consecuencia del vacío espiritual al que habían abocado el positivismo burgués y la ciencia experimental; en lo particular, ambos se enfrentaban a la política corrupta de la Restauración. Los poetas modernistas recurren por ello a la metáfora del anarquismo político para tratar de explicar una revolución que iba más allá de la estética y que afectaba al orden de los valores. No se olvide que en el prólogo a Prosas profanas (1896) Rubén Darío se había presentado como el adalid de una «estética acrática». Y no fue el único en establecer estos vínculos. En una conferencia de 1913 Manuel Machado aclaraba al público la controversia de la cuestión formal (recordemos que sobre este tema giraba el artículo de la Revista Blanca comentado más arriba) como sigue: «El modernismo, que realmente no existe ya, no fue en puridad más que una revolución literaria de carácter puramente formal. Pero relativa, no sólo a la forma externa, sino a la interna del arte. En cuanto al fondo, su característica esencial es la anarquía» ${ }^{11}$. También Federico de Onís, en su célebre antología de los años treinta, alude al modernismo como «un movimiento que se caracteriza por la intensidad y la anarquía» ${ }^{12}$. Incluso uno de sus detractores, el erudito José Deleito y Piñuela, lo tenía claro: «a los ácratas de la política corresponden los ácratas de la poesía» ${ }^{13}$. En este ambiente, con un Antonio Maura cada vez más poderoso y una imparable ola de inmigración a América, Julio Camba publica el 23 de julio de 1905 un pequeño manifiesto titulado «Afirmación». El texto debe leerse teniendo en cuenta, al menos, dos acontecimientos relevantes: el manifiesto que firman escritores como Azorín, Valle-Inclán y Baroja contra Echegaray, reciente Premio Nóbel; y sobre todo el discurso de recepción en la Real Academia que lee el poeta Emilio Ferrari en abril de 1905. Para Ferrari, discípulo de Núñez de Arce, el personalismo desaforado afín a la estética

${ }^{10}$ Ricardo Gullón, Direcciones del modernismo, Madrid, Gredos, 1963; I. A. Schulman (ed.), Nuevos asedios al modernismo, Madrid, Taurus, 1987, pp. 11-38; y María Pilar Celma VAlero, la pluma ante el espejo (visión autocrítica del «fin de siglo», 1888-1907), Salamanca, Universidad de Salamanca, 1989. La afirmación de Antonio Ramos-Gascón es rotunda al respecto de una connivencia entre lo estético y lo social: «Justicia y belleza se identifican, y quienes trabajan para la consecución de ambos ideales conviven en los mismos círculos y colaboran en los mismos órganos de expresión, en un ambiente de camaradería» («La revista Germinal y los planteamientos de la gente nueva», en VV. AA., La crisis de fin de siglo: ideología y literatura, Barcelona, Ariel, 1975, p. 141).

${ }^{11}$ Manuel Machado, «los poetas de hoy», en L. LitvaK (ed.), El modernismo, Madrid, Taurus, 1975, p. 207.

${ }^{12}$ Federico DE ONÍS (ed.), Antología de la poesía española e hispanoamericana (18821932), New York, Las Américas Publishing Company, 1961, pp. XVII-XVIII.

13 José Deleito Y PiÑUela, «¿Qué es el modernismo y qué significa como escuela dentro del arte en general y de la literatura en particular?», en L. LITVAK (ed.), op. cit., p. 384. El artículo fue publicado originalmente en Gente vieja (30 de abril, 1902). 
modernista no era índice de su modernidad, sino la prueba manifiesta de su decadencia. Anarquismo intelectual, verbalismo huero y libertinaje serán, entre otros, los núcleos sobre los que gravite su censura. Sí, para Ferrari el modernismo era un timo, y así se había encargado de satirizarlo: «es Góngora vestido a la francesa / y pringado en compota americana» ${ }^{14}$.

Camba recurre al plural colectivo - «nosotros», los jóvenes- no ya para incitar a la revolución, sino para dilucidar asuntos de poética. La idea motriz de su artículo es la de individualidad. Presenta a la juventud creadora como heterogénea y no oculta su desinterés por un modernismo «blando» personificado en el simbolismo de Juan Ramón Jiménez (acababa de aparecer su libro Jardines lejanos):

Nosotros queremos que cada uno sea juzgado por sí mismo. Entre nosotros hay católicos y anarquistas; poetas que lloran la tristeza de la luna y poetas que cantan las glorias guerreras y las futuras y terribles represalias populares. Considerar a todos los jóvenes por los pálidos lirismos de J. R. Jiménez es igual que examinar a todos los viejos por los sonetos onomásticos de Fernández Grilo.

Párrafos más adelante advertimos un Camba —ahora sí- más adepto al pensamiento anarquista de Max Stirner (Pedro Dorado había traducido El único y su propiedad en 1901 para La España Moderna). Lo reconocemos en el ejercicio de autoafirmación que realiza a partir de la idea del yo único absolutamente independiente, principio de toda relación social o moral. Nada más lejos que el imperativo categórico kantiano:

$\mathrm{Y}$ es así como unos cuantos de nosotros llegamos a aceptar todos los gérmenes de disolución, y como los elementos antisociales —en una más grande o más pequeña esfera- nos parecen siempre convenientes. [...] Yo soy enemigo de la ley, de la costumbre, de todas las cosas gregarias que impiden un mayor desarrollo de esto a lo que, si fuera filósofo, llamaría mi yo. Creo que el criminal -inconscientemente, por lo común - realiza un fin de progreso al rebelarse contra lo estatuido, y, dado el implacable determinismo de las cosas, me parece imposible fijar nunca un concepto del bien y del mal.

Camba continúa con sus divagaciones literarias. El 7 de agosto del mismo año publica en El País otro artículo titulado «La joven literatura». Insiste en motivos propios de la poética modernista como el personalismo y el afán de libertad y de novedad, aspecto que justifica una revisión crítica de la tradición literaria. Con todo, lo que me parece más interesante es la valoración que se atreve a hacer de la obra de Azorín, el que será uno de sus maestros:

${ }^{14}$ Emilio Ferrari, Obra Completa, I, Madrid, s. n., 1908-1910, p. 205. Cfr. José María MARTíneZ CACHERO, «El anti-modernismo del poeta Emilio Ferrari», Archivum, IV, 1-2, 1954, pp. 368-384. 
Yo auguro un próximo fracaso de Azorín si no rompe con esa su pose, que está bien como un fuego de artificio, para llamar la atención y hacerse el reclamo; pero que sólo puede tolerarse a cambio de algo sustancial y positivo. La simple pirotecnia, el anzuelo en seco y la pose inútil, cansarán muy pronto a las gentes.

¿Cómo cabe explicar estas reticencias? Azorín había abandonado El País por discrepancias ideológicas. Por mucho que escriba crónicas de denuncia como «La Andalucía trágica» su anarquismo literario se ha ido diluyendo. Desde junio de 1905, año en que da a la imprenta Los pueblos, colabora ya en el monárquico $A B C^{15}$. Esta evolución, parecida a la que seguirá Camba, es seguramente la que desagrada a nuestro joven inmerso en la pomada modernista, que aún le falta sudar mucha tinta para consagrarse como escritor. Con el tiempo ambos se profesarán admiración sincera. En 1917 Azorín publica una semblanza en la que se autorretrata al trasluz de la figura del personaje retratado. La rebeldía de Camba — nos explicaránace de una superioridad, de un aristocratismo ${ }^{16}$.

Finales de 1905. Valle ha publicado su Sonata de invierno y Baroja La feria de los discretos. El liberal Eugenio Montero Ríos está al frente del Gobierno. El 25 de septiembre Camba publica una crónica, «Literatura», que me parece de una importancia capital. El articulista, a través del metadiscurso, se nos presenta consciente del medio para el que escribe y de las expectativas del público. Empieza a darse cuenta de que la rebeldía es también un cliché, un convencionalismo teatral, un juego del lenguaje, el gargarismo común en la oratoria. El deseo de revolución languidece frente al spleen del otoño. Con los ojos entornados el cronista sentencia la caducidad de las grandes empresas del hombre y elogia la pureza de la fantasía:

[...] Acudimos al repertorio de lugares comunes en contra de la sociedad, de la miseria y de la ley, mientras pensamos en la bella Juanita o en la próxima y alegre cena de madrugada. ¡Oh, el amor! De cada uno de nosotros pudiera también decirse que llevamos dentro del pecho las ruinas de un poeta lírico [...]. Sabemos que así no ejercemos jamás ese hondo influjo social que nosotros mismos hemos recomendado en alguna ocasión.

En las contradicciones de una anarquía aristocratizante había hurgado con gruesas tenazas Emilio Ferrari: «Al hablar del pueblo, no lo hacen sin un desdén soberbio o una burla mordicante con dejos de feudalismo» ${ }^{17}$. Un Camba lleno de reservas acerca de la conexión entre escritura y acción acepta sus contradicciones. La retórica de la agitación se evapora en el filo

15 Véase María Dolores Dobón AnTón, Azorín anarquista: de la revolución al desencanto, Alicante, Instituto de Cultura Juan Gil-Albert, 1997.

16 Azorín, «Julio Camba», en Ni sí ni no, Barcelona, Destino, 1965, pp. 173-176.

17 Emilio FERRARI, Discursos leídos ante la Real Academia Española en la recepción de D. Emilio Ferrari, Madrid, Antonio Pérez y Compa , 1905, p. 24. 
al rojo de un cinismo sutil. Ha dado un paso atrás, se ha distanciado con impertinencia, se ha metido en la piel del eîron. Pero la metamorfosis aún no es completa. Hay que esperar un poco más.

\subsubsection{Manuel Machado, Francisco Villaespesa, Amado Nervo}

Entretanto, sigue leyendo con devoción a los líricos modernistas coetáneos. «El arte no es un conjunto de reglas, sino una armonía de caprichos», dictaminó Rubén Darío. Y Caprichos se titula el libro de Manuel Machado que comenta Camba el 25 de abril de 1905 en El País. A diferencia de otros críticos más prestigiosos como González Blanco, que le afean el derroche lúdico ${ }^{18}$, a Camba le complace su ironía espumosa y aplaude los parlamentos de Pierrot y de Arlequín. ¡Qué lejos quedan las palabras de hace unos años impresas en la Revista Blanca! Había llamado a los simbolistas franceses «fracasados de allende los Pirineos». El juicio que le merece ahora Verlaine — padre y maestro mágico según el célebre responso de Darío- es completamente distinto: «A él [Verlaine] es a quien debemos que en las viejas ramas de nuestra poesía vayan brotando estas flores de juventud. El número de poetas que las cultivan es cada vez mayor y más fuerte. Entre ellos, Manuel Machado merece consideración especial».

Camba hace lo propio con Francisco Villaespesa, otro púgil del modernismo. Reseña Rapsodias el 31 de mayo de 1905. El poeta ha dejado atrás los elementos tétricos y macabros de libros anteriores y tiende a una mayor desnudez expresiva. Así como en el caso de Machado se ponía de relieve su herencia francesa, Villaespesa «es un poeta de legítimo abolengo español, acaso el más fiel a las tradiciones de nuestra poesía y al espíritu de nuestros grandes poetas», curtido en mil batallas bohemias, entre la poesía y la taberna, entre las letras y los cafés. Camba compartió con él unos bistecs y unas tortillas en el café Universal ${ }^{19}$. Andando el tiempo nunca se olvidaría de él, siempre lo citaría con generosidad. Otra paradoja que sirve para poner en duda el anarquismo militante de Camba a la altura de 1905:

${ }_{18}$ Sobre la recepción del poemario, puede verse la introducción de Rafael ALARCón SiERrA a Manuel Machado, Alma. Caprichos. El mal poema, Madrid, Castalia, 2000, pp. 47-53.

${ }^{19}$ Francisco De Villaespesa, Poesías Completas, ed. de Federico de Mendizábal, I, Madrid, Aguilar, 1954, pp. XXXI-XXXII. Testigo de aquellas tertulias fue Eugenio D’Ors: «Éramos ocho, diez; me detalla la memoria que se encontraba entre nosotros Julio Camba, hacia aquel tiempo anarquista intelectual y a quien la fama habría de otorgar después tan merecidos lauros de humorista. Sé que nos capitaneaba Francisco Villaespesa, en cuyo vivir envidiábamos, más aún que el comercio con las musas, la intimidad profesional con los grandes escritores, tema de nuestra admiración por aquellos días; con los Machado, con Rubén Darío...» (Confesiones y recuerdos, ed. al cuidado de Alicia García Navarro, pról. de Carlos Pujol, Valencia, Pre-Textos, 2000, p. 92). 
encarece en el autor de Rapsodias su alejamiento de la realidad. Villaespesa es «inconsciente como un ruiseñor».

El texto dedicado a Amado Nervo no es una reseña, sino una presentación del autor de Jardines interiores al público español, con abundantes datos biográficos y un germen de entrevista. Interesa dejar anotada, de nuevo, la asimilación que se produce de tres conceptos: modernismo, religión y anarquía: «Amado Nervo es un místico. [...] Hoy es más fácil verlos entre los anarquistas de acción que entre los afiliados a las religiones en uso».

\subsubsection{La corte de los poetas (1906)}

En 1906 sale a la venta en la Librería Pueyo la primera antología del modernismo hispánico: La corte de los poetas. Florilegio de rimas modernas. Emilio Carrere, bohemio recalcitrante y poeta lego, es el encargado de reunir a los líricos más representativos del movimiento: Rubén Darío (el «apóstol»), los hermanos Machado, Juan Ramón Jiménez, Amado Nervo, Eduardo Marquina, Santos Chocano, Antonio de Zayas, Lugones, Villaespesa... Entre los sesenta y siete, dos ausencias: las de Valle-Inclán y Miguel de Unamuno. Carrere lanza su puya contra Ferrari, a quien califica en la nota preliminar de «compacto, abrumador, hórrido» ${ }^{20}$. En su reseña, Camba trata de refutar uno de los tópicos de la crítica anti-modernista (y de cierto anarquismo, no se olvide): la inutilidad de lo bello. La confraternidad intelectual de dos pueblos y el enriquecimiento de una lengua común son sus argumentos a favor de una utilidad más cualitativa que cuantitativa. Nótese que se combate el sentido de la utilidad burgués, materialista. De ahí la conclusión:

Véase como un libro de versos puede ser más útil todavía que un billete de ferrocarril o un manual de mecánica; véase como un canto a la luna importa de igual modo a la prosperidad de un pueblo que una estadística arancelaria y como los sembradores de flores no desempeñan una función menos trascendental que los cultivadores de patatas y hortalizas.

Ortega y Gasset no será tan generoso ni comprensivo. En una reseña aparecida en Los Lunes de El Imparcial reprueba la nueva idolatría de la palabra como puro sonido desligado del concepto. Ni que decir tiene que todavía estamos lejos de aquel notario del arte deshumanizado que ondeará la bandera del humor y de la metáfora. No es de extrañar por tanto la mofa

${ }^{20}$ Emilio CARrere, La corte de los poetas. Florilegio de rimas modernas, Madrid, Librería de Pueyo, 1906, p. 5. Cfr. José María MARTínez CACHERo, «Noticia de la primera antología del Modernismo hispánico», Archivum, XXVI, 1976, pp. 32-42. Unamuno se referirá burlonamente a la antología como «charca muerta de la Corte» (Obras Completas, III-IV, Barcelona, Vergara, p. 174). 
de una poesía que a su modo de ver se evade de la realidad, solipsista, vacía de significado trascendental:

[...] en tanto que España cruje de angustia, casi todos estos poetas vagan inocentemente en torno de los poetas de la decadencia actual francesa y con las piedras de sillería del verbo castellano quieren fingir fuentecillas versallescas, semioscuras meriendas a lo Watteau, lindezas eróticas y derretimientos nerviosos de la vida deshuesada, sonámbula y femenina de París ${ }^{21}$.

\subsubsection{Rubén Darío}

En la primavera de 1905 se realizan múltiples homenajes con motivo del III Centenario de la publicación de El Quijote. Rubén Darío está en Madrid desde febrero y lee en el Ateneo la «Salutación del optimista». El 2 de julio de ese año Camba reseña para El País los Cantos de vida y esperanza. Destaca el valor del ritmo y de la música para la nueva estética que ha introducido el poeta nicaragüense: «Esta poesía es como una trompeta monstruosa en donde la palabra adquiere sonoridades jamás oídas». El cierre del artículo es una laudatio en la que se rescata el venerable tópico del vates, del poeta inspirado que escribe para una minoría culta y sensible. El tópico se encapsula en la alegoría bíblica de la abeja laboriosa que liba la miel para las bocas delicadas:

Di tu verso como el ruiseñor dice su himno. Y sigue fabricando el panal de dulces mieles. Sé una abeja y sé como ella pródigo, generoso y fecundo. No faltarán labios voluptuosos para el panal ni para el justo sentido de la fragancia. El desdichado será aquel que no tenga gusto y no pueda saborear la dulzura eucarística, suave y embriagadora.

Desde luego Camba se niega a considerarse como una abeja obrera. El yo estético —único e infinito según el patrón romántico— no puede integrarse en una comunidad que le anula. Cuesta poco imaginar el pasmo del anarquismo populista ante la metáfora de la eucaristía aplicada a la creación. El 8 de enero de 1907 vuelve a publicar en El País un artículo mitad reseña mitad epístola dirigida al autor de Prosas profanas. No se cansa de elogiar las novedades en la métrica y el ritmo. Para Camba, el secreto está en saber leer sus versos, con las pausas y la entonación precisas. Esta vez la hipérbole irónica fluye penetrante y ambigua. ¿Qué debe ser de interés para la opinión pública, la polémica literaria o el desastre permanente de la política?:

En los círculos literarios de Madrid no se habló ayer de otra cosa que del fragmento de «El Canto Errante» publicado en El Imparcial. Esto es consolador. Creo que no tardaremos mucho en dar al mundo el admirable espectáculo de andar a tiros por un hemistiquio, aquí, donde miramos con la mayor

${ }^{21}$ José ORTEga y GASSET, «Moralejas. Poesía nueva, poesía vieja», Los Lunes de El Imparcial, 13 de agosto, 1906, p. 4. 
indiferencia cómo los malos gobiernos van haciéndonos cada vez más grandes perrerías.

A ojos de Camba, Rubén Darío congrega en torno a su original lenguaje poético toda una especie de aristocracia del espíritu. Del otro lado están aquellos que no lo entienden. Julio Camba se halla a años luz de los requerimientos del arte proletario y tiene sus razones para desconfiar de las democracias intelectuales: «Usted, maestro, habla en un dialecto que la multitud no puede comprender porque todavía no se han editado manuales para comprenderlo, ni lo enseñan en las academias de lenguas vivas [...]. Es usted un aristócrata, querido maestro, y un intransigente, y no tiene usted cabida en esta democracia intelectual donde no se toleran los privilegios». ¿En qué lugar del tablero colocamos entonces al pueblo? Rubén Darío no puede formularlo sin el auxilio de la paradoja (instrumento principal del humorismo cambiano, por cierto): "Yo no soy un poeta para las muchedumbres. Pero sé que indefectiblemente tendré que ir a ellas».

Sabemos que el discípulo llegó a tratar al maestro, ya que se conserva alguna carta en que le solicita colaboración ${ }^{22}$. Camba viajará a Nueva York con la «Oda a Roosevelt» en la cabeza y en una de sus crónicas citará de memoria «La gran cosmópolis».

\section{LA SONRISA DE UN MUERTO: HACIA LA INVENCIÓN DEL HUMORISMO}

Entre una reseña y otra ha ocurrido un hecho que va a dejar en Camba una huella profunda. El 31 de mayo de 1906 el anarquista Mateo Morral lanza una bomba desde un balcón de la calle Mayor al paso de la comitiva real. Alfonso XIII y Victoria Eugenia salen ilesos, pero hay muertos y heridos. Al poco de ser apresado, Morral se suicida de un tiro en el pecho. Camba, que había conocido al joven en la redacción de El Rebelde, va a ver el cadáver al Hospital del Buen Suceso. El cárdeno agujero en el pecho de Morral creo que simboliza para Camba el final de la utopía revolucionaria. Es un punto de inflexión crucial en su vida. Cuando el juez le toma declaración confiesa profesar ideas anarquistas, pero su distancia con respecto al anarquismo ortodoxo - lo hemos visto- comienza a ser considerable. La crónica de esta visita aparece en España Nueva un año después del atentado, cuando está teniendo lugar el proceso. Camba cierra su crónica de la visita al cadáver de Morral con un primerísimo plano: «la sonrisa de un muerto», escribe. Tiene que liberarse de algún modo de esa sonrisa siniestra, calvario de su pasado. Creo que su escepticismo y su humor nacen de la lucidez de ese desencanto. El humor es el cauterio capaz de exorcizar el fantasma turbulento de Morral. A diferencia del dogma

${ }^{22}$ Cartas de Rubén Darío. (Epistolario inédito del poeta con sus amigos españoles), Madrid, Taurus, 1963, p. 158. 
político, el humor vive de las contradicciones y alimenta las paradojas. La ironía ya había hecho acto de presencia antes de esta «escena primigenia» en que Camba se enfrenta al cadáver de la revolución. Pero pienso que es a partir de esa visión traumática cuando el humorismo se va imponiendo más como un destino que como un estilo. Ante la mirada sin vida de Morral, Camba comprende quién es sólo cuando teme lo que podría haber sido. Allí, frente a las manos al fin dóciles de quien había propagado el terror y fue su chivo expiatorio, entiende que no bastaba con cultivar el personalismo para escapar de cualquier dogma, incluido el anarquista. Caer en la sima del ego era también nocivo. El humor era la mejor medicina, aquella que permitía rebajar la pompa del yo. Era necesario también burlarse de Nietzsche y de Stirner, profetas del individualismo. En 1905, un judío vienés, Sigmund Freud publica El chiste y su relación con lo inconsciente, donde teoriza sobre lo que Camba está en trance de intuir estos años: el humor no es otra cosa que contención del sentimiento, distancia.

La salud le falla. Al poco de ocurrir el atentado y el suicidio de Morral lo vemos internado en el hospital de la caridad de las Hermanas de San Juan de Dios. No deja del todo de escribir, y prueba de ello es el texto que publica en El País el 18 de octubre: «Del hospital. La pobre muerta». El artículo tiene dos partes: la primera —en prosa- está compuesta por una breve introducción narrativa que explica la experiencia que ha originado la composición del poema que se ofrece al lector. Camba poetiza la muerte de una prostituta que acaba de morir en el hospital donde él convalece. Se trata de cuatro serventesios y de un quinteto final, en alejandrinos, estrofas que ya habían ensayado los modernistas. Lógicamente, Camba no es Rubén y los versos, cuya cadencia rítmica avanza a trasquilones, son de escaso mérito:

En sus ojos las luces del infierno cintilan ¡Sus ojos con ojeras como flores del mal! El sabor de su boca es amargo. Destilan Sus labios la ponzoña del Pecado Mortal.

Para su pecho han muerto todas las primaveras;

Una gota de sangre tiembla en cada pezón.

Dijéranse esas gotas, las dos gotas postreras

Que contuviese el débil vaso del corazón.

¡Pobre carne maldita sobre el lecho doliente!

Ya tan sólo gusanos le es posible engendrar...

Tuvo para el abrazo perfidia de serpiente

$\mathrm{Y}$ en su propio veneno hubo de envenenar.

La pálida cabeza sueña y llora. Su lloro

Purifica su alma, que va del cielo en pos.

(La pálida cabeza tiene un nimbo de oro.)

(La Magdalena es santa por la gracia de Dios.) 
Se oyen doblar dos lentas campanas funerarias.

Un silencio de muerte reina en el hospital.

La enferma abre sus hondas pupilas visionarias

$\mathrm{Y}$ en sus labios malditos florecen las plegarias

Mientras cae la lúgubre vibración del metal.

Se trata de un poema muy impostado. La atmósfera tétrica recuerda a Edgar Allan Poe y al Villaespesa de La copa del rey de Thule (1900), el que gusta de fundir eros y thánatos - pienso en «Los jardines de Afrodita». Salta a la vista el homenaje a Baudelaire y a sus Fleurs du mal. Son ecos del poeta simbolista francés la imaginería cristiana del pecado, la mujer asociada al mal y el motivo de la putrefacción del bello cuerpo femenino. Basta leer para comprobarlo poemas como «Hymne a la Beauté», «Une charogne» o «Le poison». Ha querido el azar que se conserve una brevísima carta que Camba dirige a su amigo el poeta modernista Eduardo Marquina $^{23}$ y que permite corroborar esta hipótesis. En ella, le pide que le envíe «su tomo de traducciones de Baudelaire» para hablar de ellas en $E l$ País. La traducción de Marquina en verso, que data de 1905 y fue editada por la Librería de Fernando Fe, era la primera que se hacía al castellano de Las flores del mal al completo.

Poco después Camba escribe una columna excelente donde creo que ya está lo mejor y lo más característico de su estilo: «La bomba que no ha estallado» aparece en El País el 27 de diciembre de 1906. Es una columna muy osada, pues el atentado de Morral está todavía reciente. Comenta la actualidad: el atentado fallido en Cataluña durante las Fiestas del Corpus: «En Barcelona, y nada menos que en la Rambla de las Flores, a la hora de más bullicio y de mayor alegría, se ha encontrado una bomba envuelta en un papel azul. Este presente sólo ha podido hacérselo un anarquista a la burguesía en fiestas». La ideología simplifica, refunde, compacta el pensamiento y por tanto la realidad; el humor, si es genuino, fragmenta lo real, hace del yo una entidad espongiforme y desdoblada. Desde mi punto de vista, el humor supone la superación del idealismo de juventud por cuanto inocula al pensamiento lo dinámico y lo conflictivo. Recordemos cómo era el discurso de El Rebelde: un arrebato propagandístico, una palabra de agitación trabada a base de anáforas y módulos apelativos. El dogma fortalece al yo con un relato explicativo, reconfortante; el humor también fortalece al yo, pero sin cegarlo, haciendo que se ponga frente al objeto sin confundirse con él. A la conciencia absoluta opone la conciencia contingente, antipatética, digresiva. Existe, además, un motivo añadido que hace

23 Andrés Amorós, Correspondencia a Eduardo Marquina, Madrid, Castalia, 2005, p. 246. Curiosamente, en su artículo de la Revista Blanca Camba, aunque la aprecia, no acepta del todo la poesía de Marquina: «Otro espíritu joven tenemos también: Eduardo Marquina; pero éste carece —en mi sentir- de un íntegro temperamento poético». 
incompatibles el credo anarquista y el humorismo. El primero se sustenta en el racionalismo metafísico y gnoseológico propio de la modernidad. Por el contrario, el humor surge de una actitud ante la vida escéptica y desapasionada, lo cual permite alojar tanto la autoironía como el absurdo, la indeterminación permanente. Sólo si tomamos el anarquismo en sentido figurado puede decirse que también el humor es una escuela de subversión de la moral gregaria y masificada.

Anarquista militante o anarquista literario con el beso de la aristocracia y el lino de los manteles, no cabe duda de que Julio Camba entendió que la huida, el viaje era un modo de revolución encubierta. Había que rozar el ego en todas las esquinas del mundo, despilfarrarlo por las aceras. Pocos años después, con una maleta medio vacía, se marchó a Constantinopla. A bordo del vapor, al mirar por el ojo de buey, tal vez recordase la sonrisa grotesca de Mateo Morral perdiéndose en la bruma. 